\section{BMJ Paediatrics Open}

\title{
Anxiety in children attending a specialist inherited cardiac arrhythmia clinic: a questionnaire study
}

\author{
Anna Natalia Last, ${ }^{1}$ Jennifer English, ${ }^{2}$ Helen Pote, ${ }^{1}$ Roz Shafran, ${ }^{2}$ Tamsin Owen, \\ Juan Pablo Kaski ${ }^{2,3}$
}

To cite: Last AN, English J, Pote $\mathrm{H}$, et al. Anxiety in children attending a specialist inherited cardiac arrhythmia clinic: a questionnaire study. BMJ Paediatrics Open 2018;2:e000271. doi:10.1136/ bmjpo-2018-000271

Received 20 February 2018 Revised 1 May 2018 Accepted 19 May 2018
Check for updates

(C) Author(s) (or their employer(s)) 2018. Re-use permitted under CC BY-NC. No commercial re-use. See rights and permissions. Published by BMJ.

${ }^{1}$ Department of Psychology, University of Royal Holloway, London, UK

${ }^{2}$ Centre for Inherited Cardiovascular Diseases, Great Ormond Street Hospital, London, UK

${ }^{3}$ Institute of Cardiovascular Science, University College London, London, UK

Correspondence to Dr Juan Pablo Kaski; j.kaski@ ucl.ac.uk

\section{ABSTRACT}

Objectives Inherited cardiac arrhythmia syndromes are life-threatening conditions. There is a paucity of research examining the psychological impact of these conditions in children. This study had three main aims. The first was to explore how the Cardiac Anxiety Questionnaire (CAQ) performs in a child population. The second aim was to compare the level of anxiety of children with an inherited cardiac arrhythmia syndrome and children being screened due to a family history of an inherited cardiac arrhythmia syndrome to control children. The third aim was to examine associations between a sudden cardiac death in the immediate family and levels of anxiety.

Method 47 children with an inherited cardiac arrhythmia syndrome, 78 children with a family history and 75 control children completed the Revised Child Anxiety and Depression Scale (RCADS), the Cardiac Anxiety Questionnaire for Children (CAQ-C) and the Childhood Anxiety Sensitivity Index. Children were between the age of 8 and 16 years.

Results The study found the $\mathrm{CAQ}-\mathrm{C}$ had promising psychometric properties. There were no significant differences in total anxiety scores (as measured by the RCADS) between the three groups. There were significant differences in cardiac-focused anxiety scores between the three groups.

Conclusions The CAQ has promising psychometric properties in a child population. However, further research is needed. Children attending specialist inherited cardiac arrhythmia clinics should be targeted for routine psychological screening and offered psychological intervention where necessary.

\section{INTRODUCTION}

Inherited cardiac arrhythmia syndromes are a group of life-threatening conditions that leave children at risk of sudden cardiac death (SCD). ${ }^{1}$ There are several different types of inherited cardiac arrhythmia syndromes including: long QT syndrome (LQTS), Brugada syndrome, catecholaminergic polymorphic ventricular tachycardia, short QT syndrome and early repolarisation syndrome. ${ }^{1}$ Inherited cardiac arrhythmia syndromes affect approximately 1 in 2000 people. ${ }^{1}$ They are inherited in an autosomal

\section{What is already known on this topic?}

The limited research that exists suggests children attending a specialist inherited cardiac arrhythmia clinic may experience elevated levels of anxiety. Eifert et al describe a cognitive behavioural model of cardiac-focused anxiety in adults that could be applied to help explain the distress these children may experience. A measure of cardiac-focused anxiety has been developed in adults but not in children.

\section{What this study hopes to add?}

The study explored how the Cardiac Anxiety Questionnaire performs in a child population. This allows an examination of cardiac-focused anxiety in children with an inherited cardiac arrhythmia syndrome and children being screened due to a family history for the first time. Equally it is the first time associations between clinical variables and high levels of anxiety in these groups have been examined.

dominant manner. This means children and siblings of those affected have a $50 \%$ chance of inheriting the condition. ${ }^{1}$ Unfortunately, these conditions do not always present with symptoms. and test abnormalities are often intermittent creating a complex diagnostic process. ${ }^{1}$ These conditions can also develop over time, which means ongoing screening is required for children who have been diagnosed and children who have a family history. ${ }^{1}$

The life-threatening nature of these conditions and the strong hereditary pattern are likely to create significant anxiety. Furthermore, the complex diagnostic process and the need for ongoing monitoring can create much uncertainty. A growing body of research had demonstrated a relationship between illness uncertainty and anxiety in childhood illness. ${ }^{2}$ Despite this, very little research has focused on the psychological impact of these conditions in children. 
Meulenkamp et $a \hat{l}$ conducted a qualitative study and found children with LQTS worried about the effectiveness of their medication and possible SCD. Guifre et $a t^{t}$ conducted a quantitative study comparing 40 children with asthma to 7 children with LQTS. The results suggested children with LQTS experienced significant anxiety. However, the small sample size and the absence of a control group limit conclusions that can be drawn.

Previous research has also not considered how psychological theory may explain the distress these children may experience. Eifert et a $\check{l}$ describe a cognitive behavioural model of cardiac-focused anxiety in adults. The model draws on empirically supported models of panic disorder ${ }^{6}$ and health anxiety ${ }^{7}$ but is specifically related to the heart. The model could be applied to help understand the distress these children may experience.

Eifert $e t a l^{8}$ developed the brief self-report Cardiac Anxiety Questionnaire (CAQ) to aid the diagnosis of cardiac-focused anxiety in adults presenting at busy medical settings. However, there is no measure of cardiac-focused anxiety in children.

Due to the lack of previous research, the proposed study aimed to:

- Explore how the CAQ performs in a child population.

- Compare the level of anxiety of children with an inherited cardiac arrhythmia syndrome and children being screened due to a family history to control children.

- Examine the association between SCD in the immediate family and levels of anxiety.

\section{METHOD}

\section{Participants}

A total of 200 children participated in the study as detailed below.

\section{Specialist inherited cardiac arrhythmia clinic}

The specialist inherited cardiac arrhythmia clinic ran weekly at a national paediatric hospital. This clinic is the largest in Europe, and there are few other clinics in the UK. Between July and December 2015, children with an inherited cardiac arrhythmia syndrome or a family history who attended the specialist inherited cardiac arrhythmia clinic were invited to take part. The researcher approached consecutive patients in clinic. One hundred and fifty-six children (between the ages of 8 and 16 years) were approached. Eighty per cent $(n=125)$ agreed to take part. Forty-seven children had an inherited cardiac arrhythmia syndrome, and 78 children were being screened due to a family history.

\section{Control}

Four local primary and four secondary schools were approached using an opportunistic sampling method. One primary school and one secondary school agreed to take part. A class from each year group (years 4-11) were randomly selected. Two hundred and forty control children (between the ages of 8 and 16 years) who did not have a cardiac condition or were not screened regularly due to a family history were invited to take part from a local primary and secondary school. Thirty-one per cent $(n=75)$ of children agreed to take part.

\section{Measures}

All children completed the CAQ-C, the Childhood Anxiety Sensitivity Index (CASI $)^{9}$ and the Revised Children's Anxiety and Depression Scale (RCADS) ${ }^{10}$ Medical information was extracted from the child's medical notes.

\section{Cardiac Anxiety Questionnaire for Children (CAQ-C)}

The CAQ-C was chosen to assess cardiac-focused anxiety in children. The CAQ is an 18-item self-report questionnaire designed for adults. ${ }^{8}$ Items are rated on a 5-point Likert scale from 0 (never) to 4 (always). The CAQ yields a total cardiac-focused anxiety score. It also has three subscales: fear, avoidance and attention. Eifert $e t a l^{8}$ reported favourable validity and reliability in a clinical population. Minor adaptations were made to make the questionnaire child friendly. Please contact the corresponding author for a copy.

\section{Childhood Anxiety Sensitivity Index}

The CASI was chosen as a child appropriate measure of anxiety sensitivity. ${ }^{9}$ The adult version of the CASI showed moderate correlations with the CAQ in an adult sample. The CASI assesses an individual's level of fear of anxiety-related symptoms (eg, rapid heartbeat) based on the belief that such sensations have harmful consequences. It is designed for children between the ages of 6 and 17 years. The CASI is an 18-item self-report questionnaire. Items are rated on a 3-point Likert scale from 1 (none) to 3 (a lot). The CASI yields a total score. Silverman et a $f^{9}$ report favourable validity and reliability in a clinical and non-clinical population.

\section{Revised Children's Anxiety and Depression Scale}

The RCADS was used because it is a comprehensive and psychometrically sound measure of anxiety in children. ${ }^{10}$ The RCADS is a 47-item self-report questionnaire. Items are rated on a 4-point Likert scale as to how frequently the behaviour typically occurs from 0 (never) to 3 (always). The RCADS yields a total anxiety score. Chorpita $e t a l^{10}$ and Chorpita $e a^{11}$ reported favourable validity and reliability in a clinical and non-clinical population.

\section{Procedure}

Children attending the specialist inherited cardiac arrhythmia clinic completed questionnaires before or in between their medical assessments but before they saw the consultant cardiologist. The control children were invited to take part during school time.

\section{Data analysis}

All data were analysed using SPSS (V.21) and checked once for inaccuracies.

No questionnaire item had more than $5 \%$ missing values across the sample. Therefore, no further investigations regarding missing data were conducted..$^{12}$ If an 
individual questionnaire had missing data, these were excluded from subsequent analyses. ${ }^{12}$

Outliers were also identified and removed. ${ }^{12}$ Outliers represent data values that deviate from the other observations. Any score that deviates more than three SD from the mean of that variable is considered an outlier and should be removed. ${ }^{12}$ Outliers were examined for the CAQ total cardiac-focused anxiety score and the CAQ subscale (fear, avoidance and attention) scores, the RCADS total anxiety score and the CASI total anxiety sensitivity score. This analysis was conducted for each of the three groups separately. A sensitivity analysis found the results did not alter when outliers were included.

The sample size for all groups was greater than 30 and therefore parametric tests were appropriate. ${ }^{12}$

Confounding variables were identified and their impact on the analysis considered.

Cronbach's alphas were calculated to establish the internal consistency of the total CAQ score and the CAQ subscale (fear, avoidance and attention) scores in a child population. This analysis included all children (children with an inherited cardiac arrhythmia syndrome, children being screened due to a family history of an inherited cardiac arrhythmia syndrome and control children).

A Pearson's correlation was performed to examine the association between the $\mathrm{CAQ}$ total/subscale (fear, avoidance and attention) scores and the CASI total score in a child population. This analysis included all children (children with an inherited cardiac arrhythmia syndrome, children being screened due to a family history of an inherited cardiac arrhythmia syndrome and control children).

A one-way independent analysis of variance (ANOVA) was conducted to see if the three groups (children with an inherited cardiac arrhythmia syndrome, children being screened due to a family history of an inherited cardiac arrhythmia syndrome and control children) differed significantly on their total anxiety score on the RCADS. Where there were significant results, three pairwise post hoc independent sample t-tests were carried out to establish where the exact difference lies. Bonferroni corrections were not applied because there are only three comparisons being made. ${ }^{12}$

A series of one-way independent ANOVAs were conducted to see if the three groups (children with an inherited cardiac arrhythmia syndrome, children being screened due to a family history of an inherited cardiac arrhythmia syndrome and control children) differed significantly on their CAQ total cardiac-focused anxiety scores and their CAQ subscale (fear, avoidance and attention) scores. Where there were significant results three pairwise post hoc independent sample t-tests were carried out to establish where the exact differences lie. Bonferroni corrections were not applied because there were only three comparisons for each scale or subscale, and each scale or subscale analysis can be considered a self-contained analysis. ${ }^{12}$
Independent sample t-tests were carried out to see if those who have experienced an SCD in the immediate family have higher levels of total cardiac-focused anxiety than those who have not. A separate analysis was conducted for children with an inherited cardiac arrhythmia syndrome and children being screened due to a family history of inherited cardiac arrhythmias syndromes. The control children were not included in this analysis.

\section{RESULTS}

\section{Characterising the sample}

Table 1 shows the demographic characteristics of the sample.

Tables 2 and 3 show the clinical characteristics of the children attending the specialist inherited cardiac arrhythmia clinic

\section{Confounding variables}

Age and gender have previously been shown to be associated with anxiety in children. ${ }^{10}$ The impact of age on RCADS total anxiety and CAQ-C total cardiac-focused anxiety scores within this sample were examined using a Pearson's correlation. Across the sample, there was no significant correlation between age and RCADS total anxiety scores $(\mathrm{r}(161)=0.02, \mathrm{p}=0.76)$ or between age and total CAQ-C cardiac-focused anxiety scores $(\mathrm{r}(196)=0.13$, $\mathrm{p}=0.07$ ) scores. Therefore, age was not controlled for in subsequent analysis. The impact of gender on RCADS total anxiety and CAQ-C total cardiac-focused anxiety scores within this sample were examined using an independent t-test. Females had significantly higher scores than males on their total RCADS scores $(\mathrm{t}(163)=4.6$, $\mathrm{p}<0.001) \quad(95 \% \mathrm{CI} 13.64$ to 5.45$)$. The mean score for females was 29.91, and the mean scores for males was 20.37. Females and males did not differ on their total CAQ-C cardiac-focused anxiety scores $(\mathrm{t}(187)=0.73$, $\mathrm{p}=0.46,95 \% \mathrm{CI} 0.22$ to 0.10$) \mathrm{A} \chi^{2}$ was conducted to establish whether the three groups (children with an inherited cardiac arrhythmia syndrome, children being screened due to a family history of an inherited cardiac arrhythmia syndrome and control children) differed on their gender distribution. The groups did not differ on their gender distribution $\left(\chi^{2}(2)=2.2, p=0.34\right)$. Therefore, gender was not controlled for in subsequent analysis.

\section{Psychometric properties of the CAQ-C Internal consistency}

The Cronbach's alpha coefficient for the total CAQ-C score was in the good range $(\alpha=0.83)$. The Cronbach's alpha coefficients for the subscales were in the marginal to good range (table 4$)$.

\section{Convergent validity}

A Pearson correlation found there was a significant positive correlation between the CAQ total score and the CASI $(\mathrm{r}(170)=0.62, \mathrm{p}<0.001)$. The Pearson correlation 
Table 1 Demographic characteristics of the sample

\section{Children diagnosed with an Children being screened inherited cardiac arrhythmia \\ syndrome $(n=47)$ due to a family history of an inherited cardiac}

\begin{tabular}{|c|c|c|c|}
\hline & syndrome $(n=47)$ & arrhythmia syndrome $(n=78)$ & Control children $(n=75)$ \\
\hline \multicolumn{4}{|l|}{ Age of child, years } \\
\hline Mean (SD) & $13.18(2.34)$ & $12.90(2.58)$ & $12.08(2.39)$ \\
\hline Minimum/maximum & $8.40 / 16.49$ & $8.05 / 16.91$ & $8.24 / 15.99$ \\
\hline \multicolumn{4}{|l|}{ Gender, n (\%) } \\
\hline Male & $21(45)$ & $37(48)$ & $27(36)$ \\
\hline Female & $26(55)$ & $41(52)$ & $48(64)$ \\
\hline \multicolumn{4}{|l|}{ Ethnicity, n (\%) } \\
\hline White & $30(64)$ & $53(68)$ & $63(84)$ \\
\hline Black or black British & $5(11)$ & $10(13)$ & $4(5)$ \\
\hline Mixed & $4(9)$ & $8(10)$ & $5(7)$ \\
\hline Asian or Asian British & $6(13)$ & $6(8)$ & $0(0)$ \\
\hline Chinese & $0(0)$ & $0(0)$ & $0(0)$ \\
\hline Other & $0(0)$ & $0(0)$ & $2(3)$ \\
\hline Missing & $2(4)$ & $1(1)$ & $1(1)$ \\
\hline \multicolumn{4}{|l|}{ Family structure, n (\%) } \\
\hline Nuclear family & $29(62)$ & $49(62)$ & $63(84)$ \\
\hline Single parent & $14(30)$ & $17(22)$ & 7 (9) \\
\hline Step family & $3(6)$ & 7 (9) & $4(5)$ \\
\hline Extended family & $1(2)$ & $3(4)$ & $0(0)$ \\
\hline Children in care & $0(0)$ & $2(3)$ & $0(0)$ \\
\hline Missing & $0(0)$ & $0(0)$ & $1(1)$ \\
\hline \multicolumn{4}{|l|}{ Socioeconomic status, n (\%) } \\
\hline $\begin{array}{l}\text { Higher managerial, administrative } \\
\text { and professional occupations }\end{array}$ & $14(30)$ & $25(32)$ & $7(9)$ \\
\hline $\begin{array}{l}\text { Lower managerial, administrative and } \\
\text { professional occupations }\end{array}$ & $5(11)$ & $20(26)$ & $36(48)$ \\
\hline Intermediate occupations & $2(4)$ & $3(4)$ & $5(7)$ \\
\hline $\begin{array}{l}\text { Small employers and own account } \\
\text { workers }\end{array}$ & $0(0)$ & $1(1)$ & $4(5)$ \\
\hline $\begin{array}{l}\text { Lower supervisory, craft and related } \\
\text { occupations }\end{array}$ & 9 (19) & $13(17)$ & 7 (9) \\
\hline Semi routine occupations & $10(21)$ & $8(10)$ & $5(7)$ \\
\hline Routine occupations & $3(6)$ & $3(4)$ & $3(4)$ \\
\hline Unemployed & $4(9)$ & $1(1)$ & $0(0)$ \\
\hline Missing & $0(0)$ & $4(5)$ & $8(11)$ \\
\hline
\end{tabular}

coefficient indicates the correlation between the CAQ total score and the CASI was in the good range (table 5).

A Pearson correlation found there was a significant positive correlation between the CAQ fear subscale and the CASI $(r(168)=0.56, p<0.001)$. The Pearson correlation coefficient indicates the correlation between the CAQ fear subscale score and the CASI was in the good range (table 5).

A Pearson correlation found there was a significant positive correlation between the CAQ avoidance subscale and the CASI $(\mathrm{r}(170)=0.39, \mathrm{p}<0.001)$. The Pearson correlation coefficient indicates the correlation between the CAQ avoidance subscale score and the CASI was in the acceptable range (table 5).

A Pearson correlation found there was a significant positive correlation between the CAQ attention subscale and the CASI $(\mathrm{r}(167)=0.46, \mathrm{p}<0.001)$. The Pearson correlation coefficient indicates the correlation between the CAQ attention subscale score and the CASI was in the acceptable range (table 5 ). 
Table 2 Clinical characteristics of the children diagnosed with an inherited cardiac arrhythmia syndrome

\section{Children diagnosed with an inherited cardiac arrhythmia syndrome $(n=47)$}

\begin{tabular}{lc}
\hline Time since diagnosis, days & \\
\hline Mean (SD) & 1444.31 (1062.27) \\
\hline Minimum/maximum (range) & $42 / 4678$ (4636) \\
\hline Diagnosis, n (\%) & $29(62)$ \\
\hline Long QT syndrome & $11(23)$ \\
\hline Brugada syndrome & $5(11)$ \\
\hline Catecholaminergic polymorphic & $1(2)$ \\
ventricular tachycardia & $1(2)$ \\
\hline Short QT syndrome & \\
\hline Unknown & $27(57)$ \\
Symptoms, n (\%) & $20(43)$ \\
\hline No & \\
\hline Yes & $44(94)$ \\
\hline Out-of-hospital cardiac arrest, n (\%) & $3(6)$ \\
\hline No & \\
\hline Yes & $13(28)$ \\
\hline Treatment, n (\%) & $27(57)$ \\
\hline None & $7(15)$ \\
\hline Medication & \\
\hline Medication+lCD & \\
\hline No & \\
\hline
\end{tabular}

ICD, implantable cardioverter-defibrillator; SCD, sudden cardiac death.

A one-way independent ANOVA showed the three groups (children with an inherited cardiac arrhythmia syndrome, children being screened due to a family history and control children) did not differ significantly on their RCADS scores $(\mathrm{F}(2,162)=2.64, \mathrm{p}=0.07)$ (table 6). Therefore, no follow-up t tests were conducted.

A one-way independent ANOVA showed the three groups differed significantly on their total CAQ-C scores $(\mathrm{F}(2,186)=6.02, \mathrm{p}=0.003)$. Pairwise post hoc t-tests show that children with an inherited cardiac arrhythmia syndrome scored significantly higher than children being screened due to a family history $(\mathrm{t}(67)=2.85, \mathrm{p}=0.006$, $95 \%$ CI 0.09 to 0.54 ). Children with an inherited cardiac arrhythmia syndrome also scored significantly higher than control children $(\mathrm{t}(109)=3.03, \mathrm{p}=0.003,95 \%$ CI 0.11 to 0.54 ). There were no significant differences between children being screened due to a family history and control children $(\mathrm{t}(146)=0.15, \mathrm{p}=0.88,95 \%$ CI 0.15 to $0.18)$.

A one-way independent ANOVA showed the three groups differed significantly on their CAQ-C fear scores
Table 3 Clinical characteristics of the children being screened due to a family history of an inherited cardiac arrhythmia syndrome

Children being screened due to a family history of an inherited cardiac arrhythmia syndrome $(n=78)$

\begin{tabular}{|c|c|}
\hline Mean (SD) & 1285 \\
\hline Minimum/maximum (range) & 0.00/3976.00 (3976.00) \\
\hline \multicolumn{2}{|l|}{ Diagnosis in family, n (\%) } \\
\hline SADS & $30(39)$ \\
\hline Long QT syndrome & $21(27)$ \\
\hline Brugada syndrome & $16(21)$ \\
\hline Unknown & $11(14)$ \\
\hline \multicolumn{2}{|c|}{ History of SCD in immediate family, n (\%) } \\
\hline No & $47(60)$ \\
\hline Yes & $31(40)$ \\
\hline
\end{tabular}

SADS, sudden arrhythmia death syndrome; SCD, sudden cardiac death.

$(\mathrm{F}(2,184)=6.23, \mathrm{p}=0.002)$. Pairwise post hoc t-tests show that children with an inherited cardiac arrhythmia syndrome scored significantly higher than children being screened due to a family history $(\mathrm{t}(115)=3.57, \mathrm{p}=0.001$, 95\% CI 0.17 to 0.60$)$. Children with an inherited cardiac arrhythmia syndrome also scored significantly higher than control children $(\mathrm{t}(109)=2.80, \mathrm{p}=0.006,95 \%$ CI 0.10 to 0.61$)$. There were no significant differences between children being screened due to a family history and control children $(\mathrm{t}(130)=0.27, \mathrm{p}=0.79,95 \%$ CI 0.22 to 0.17) (table 6).

A one-way independent ANOVA showed the three groups differed significantly on their CAQ-C avoidance scores $(\mathrm{F}(2,186)=3.23, \mathrm{p}=0.04)$. Pairwise post hoc t-tests show that children with an inherited cardiac arrhythmia syndrome scored significantly higher than children being screened due to a family history $(\mathrm{t}(63)=2.05, \mathrm{p}=0.04,95 \%$ CI 0.01 to 0.74$)$. There were no significant differences between children being screened due to a family history and control children $(\mathrm{t}(146)=0.25, \mathrm{p}=0.80,95 \%$ CI 0.27 to 0.21$)$. There were also no significant differences

Table 4 Internal consistency of the CAQ-C in a child population $(n=189)$

\begin{tabular}{lll}
\hline & \multicolumn{2}{l}{ Cronbach value Standard } \\
\hline CAQ-C total scale & $0.83^{*}$ & Good \\
CAQ-C Fear & $0.70^{*}$ & Acceptable \\
CAQ-C Avoidance & $0.82^{*}$ & Good \\
CAQ-C Attention & $0.64^{*}$ & Marginal
\end{tabular}

${ }^{*} \mathrm{P}=<0.001$.

CAQ-C, Cardiac Anxiety Questionnaire for Children. 
Table 5 Convergent validity of the CAQ and CAS

\begin{tabular}{lll}
\hline & CASI & Standard \\
\hline $\begin{array}{l}\text { CAQ-C total scale } \\
(n=172)\end{array}$ & $0.62^{*}$ & Good \\
$\begin{array}{l}\text { CAQ-C Fear } \\
(n=170)\end{array}$ & $0.56^{*}$ & Good \\
$\begin{array}{l}\text { CAQ-C Avoidance } \\
(n=172)\end{array}$ & $0.39^{*}$ & Acceptable \\
$\begin{array}{l}\text { CAQ-C Attention } \\
(n=169)\end{array}$ & $0.46^{*}$ & Acceptable \\
\hline
\end{tabular}

Note: different $\mathrm{N}$ values are due to different patterns of missing data and different number of outliers across the CAQ and the CASI.

Anxiety in children attending a specialist inherited cardiac arrhythmia clinics

${ }^{*} P<0.001$.

CAQ, Cardiac Anxiety Questionnaire; CASI, Childhood Anxiety

Sensitivity Index.

between children with an inherited cardiac arrhythmia syndrome and control children $(\mathrm{t}(63)=1.88, \mathrm{p}=0.06,95 \%$ CI 0.02 to 0.71 ) (table 6 ).
A one-way independent ANOVA showed the three groups did not differ significantly on their CAQ-C attention scores $(\mathrm{F}(2,183)=2.64, \mathrm{p}=0.07)$. Therefore, no follow-up t-tests were conducted (table 6).

Twelve per cent of children with an inherited cardiac arrhythmia syndrome had an SCD in the immediate family and $60 \%$ of children with a family history of an inherited cardiac arrhythmia syndrome had an SCD in the immediate family.

An independent t-test found there were no significant differences in total cardiac-focused anxiety between children with an inherited cardiac arrhythmia syndrome who had experienced an SCD in the immediate family and children with an inherited cardiac arrhythmia syndrome who had not experienced an SCD in the immediate family $(\mathrm{t}(39)=1.13, \mathrm{p}=0.27,95 \%$ CI 0.92 to 0.26) (table 7).

An independent t-test found children being screened due to a family history who had experienced an SCD in the immediate family had higher total cardiac-focused anxiety scores than children being screened due to a family history who had not experienced an SCD in the

Table 6 Mean RCAD and CAQ-C scores

\begin{tabular}{|c|c|c|c|c|}
\hline & $\begin{array}{l}\text { Cardiac arrhythmia } \\
\text { syndrome }\end{array}$ & Family history & Control & $\begin{array}{l}\text { ANOVA } \\
P \text { values }\end{array}$ \\
\hline \multicolumn{5}{|l|}{ RCAD total anxiety score } \\
\hline $\mathrm{N}$ & 38 & 64 & 63 & \\
\hline Mean (SD) & $24.76(15.24)$ & 23. 22 (11.22) & $28.76(15.38)$ & \\
\hline Minimum/maximum (range) & 2/54(52) & 7/53(46) & $3 / 68(65)$ & \\
\hline \multicolumn{5}{|c|}{ CAQ-C total cardiac-focused anxiety } \\
\hline $\mathrm{N}$ & 41 & 78 & 70 & \\
\hline Mean (SD) & $1.24(0.62){ }^{*} \dagger$ & $0.93(0.49)$ & $0.92(0.51)$ & \\
\hline Minimum/maximum (range) & $0.39 / 2.83(2.44)$ & $0.22 / 2.39(2.14)$ & $0.06 / 2.28(2.22)$ & 0.003 \\
\hline \multicolumn{5}{|l|}{ CAQ-C Fear } \\
\hline $\mathrm{N}$ & 41 & 76 & 70 & \\
\hline Mean (SD) & $1.42(0.63)^{*} \dagger$ & $1.04(0.51)$ & $1.07(0.66)$ & \\
\hline Minimum/maximum (range) & $0 / 3(3)$ & $0.13 / 2.50(2.37)$ & $0.00 / 2.63(2.63)$ & 0.002 \\
\hline \multicolumn{5}{|l|}{ CAQ-C Avoidance } \\
\hline $\mathrm{N}$ & 41 & 78 & 70 & \\
\hline Mean (SD) & $1.12(1.04)^{*}$ & $0.74(0.75)$ & $0.77(0.72)$ & \\
\hline Minimum/maximum (range) & $0.00 / 3.60(3.6)$ & $0.00 / 3.00(3)$ & $0.00 / 2.40(2.4)$ & 0.04 \\
\hline \multicolumn{5}{|l|}{ CAQ-C Attention } \\
\hline $\mathrm{N}$ & 40 & 77 & 69 & \\
\hline Mean (SD) & $1.03(0.56)$ & $0.82(0.54)$ & $0.79(0.54)$ & \\
\hline Minimum/maximum (range) & $0.20 / 2.20(2)$ & $0.00 / 2.60(2.60)$ & $0.00 / 2.20(2)$ & 0.07 \\
\hline
\end{tabular}

Note: different $\mathrm{N}$ values are due to different patterns of missing data and different number of outliers across the RCADS and CAQ-C. Associations between SCD in the immediate family and levels of anxiety.

${ }^{*}$ Pairwise post hoc t-tests indicate significant differences between children with an inherited cardiac arrhythmia syndrome and children being screened due to a family history of an inherited cardiac arrhythmia syndrome $(p<0.05)$.

†Pairwise post hoc t-tests indicate significant differences between children with an inherited cardiac arrhythmia syndrome and control children $(p<0.05)$.

CAQ-C, Cardiac Anxiety Questionnaire for Children; RCADS, Revised Children's Anxiety and Depression Scale; SCD, sudden cardiac death. 
Table 7 Anxiety in children who have experienced an SCD in the immediate family

Cardiac
arrhythmia
syndrome and
SCD in the
immediate family
$(n=5)$

Cardiac arrhythmia syndrome with no SCD in the immediate family $(n=36)$

\begin{tabular}{|c|c|c|c|}
\hline $\begin{array}{l}\text { T-test } P \\
\text { values }\end{array}$ & $\begin{array}{l}\text { Family history } \\
\text { and SCD in the } \\
\text { immediate family } \\
(\mathrm{n}=47)\end{array}$ & $\begin{array}{l}\text { Family history } \\
\text { with no SCD in } \\
\text { the immediate } \\
\text { family ( } n=31 \text { ) }\end{array}$ & $\begin{array}{l}\text { T-test } \\
\mathbf{P} \\
\text { values }\end{array}$ \\
\hline
\end{tabular}

CAQ-C

Total cardiac-focused anxiety

score:

\begin{tabular}{|c|c|c|c|c|c|}
\hline Mean (SD) & $1.53(0.58)$ & $1.20(0.62)$ & & $1.08(0.56)$ & $0.83(0.42)$ \\
\hline & & & 0.27 & & 0.03 \\
\hline Minimum/maximum (range) & $0.94 / 2.391 .44)$ & $0.39 / 2.83(2.44)$ & & $0.22 / 2.39(2.17)$ & $0.22 / 1.94(1.72)$ \\
\hline
\end{tabular}

CAQ-C, Cardiac Anxiety Questionnaire for C hildren; SCD, sudden cardiac death.

immediate family $(\mathrm{t}(76)=2.2, \mathrm{p}=0.03,95 \%$ CI 0.47 to 0.03) (table 7).

\section{DISCUSSION}

\section{Overview}

This study had three aims. The first was to explore how the CAQ-C performs in a child population. The second was to compare the level of anxiety of children with an inherited cardiac arrhythmia syndrome and children being screened due to a family history to control children. The third was to examine the association between SCD in the immediate family and levels of anxiety.

\section{Findings}

Reliability analysis showed that the internal consistency of the CAQ-C total scale and subscales were adequate in a child population. Specifically internal consistency values were in the marginal to good range. The significant correlation between the CAQ-C total scale and the CASI, and the significant correlations between the CAQ-C subscales and the CASI, indicates the CAQ-C also had adequate convergent validity properties within a child population.

Together, the reliability and validity analysis indicates that the CAQ-C has promising psychometric properties.

There were no significant differences in total anxiety scores (as measured by the RCADS) between children with an inherited cardiac arrhythmia syndrome, children being screened due to a family history and control children. However, there were significant differences in total cardiac-focused anxiety scores (as measured by the CAQ-C). Children with an inherited cardiac arrhythmia syndrome had significantly higher total cardiac-focused anxiety scores than children being screened due to a family history. There were no significant differences between children being screened due to a family history and control children. A similar pattern was evident for the CAQ-C fear scale. A slightly different pattern was evident for the CAQ-C avoidance scale. Children with an inherited cardiac arrhythmia syndrome scored significantly higher than children being screened due to a family history.
There were no significant differences between children being screened due to a family history and control children. There were also no significant differences between children diagnosed with an inherited cardiac arrhythmia syndrome and control children. However, it is likely this slight exception is due to the smaller sample size of the inherited cardiac arrhythmia group and a consequent slight lack of power. Contrastingly, there were no significant differences in CAQ-C attention scores between the three groups. Again, this could be due to lack of power. However, it could also be that items such as 'I can feel my heart in my chest' and 'I check my pulse' are less relevant to children compared with adults because children do not have the cognitive understanding of their condition to monitor themselves in such a manner.

This study also examined the associations between SCD in the immediate family and anxiety. There were no significant differences in total cardiac-focused anxiety between children with an inherited cardiac arrhythmia syndrome who had experienced an SCD in the immediate family and children with an inherited cardiac arrhythmia syndrome who had not experienced an SCD in the immediate family. This could be due to a lack of power. It may also be that these children experience heightened cardiac-focused anxiety due to their condition regardless of whether they have also experienced an SCD in the immediate family. In contrast, children being screened due to a family history who had experienced an SCD in the immediate family had higher total cardiac-focused anxiety scores than children being screened due to a family history who had not experienced an SCD.

\section{Clinical implications}

Questionnaires used to measures Diagnostic and Statistical Manual of Mental Disorders, 5th Edition (DSM-V) specific categories of anxiety (such as the RCADS) may be less relevant to children with an inherited cardiac arrhythmia syndrome and children who have a family history of such conditions. These questionnaires do not seem sensitive to the distress these children experience 
that questions their utility in clinical practice. The CAQ has promising psychometric properties in a child population. Furthermore, the brevity of the CAQ means it is not time consuming to complete and so is appropriate for use in busy medical settings.

Children with a cardiac arrhythmia syndrome and children who have a family history who have experienced an SCD in the immediate family are at risk of experiencing cardiac-focused anxiety. These children should be targeted for routine screening and offered psychological input where necessary. Research suggests cognitivebehavioural therapy could be an effective treatment. ${ }^{13}$ Eifert $e t a l \mathrm{~s}^{5}$ cognitive behavioural model of cardiac-focused anxiety in adults could be applied to help understand the distress these children experience and has direct treatment implications. ${ }^{14}$

\section{Limitations}

The current study only provides a preliminary examination of the psychometric properties of the CAQ-C. The retest reliability and norms/clinical cut-offs for the CAQ-C need to be established before it can be used routinely in clinical practice.

The sample size for the children with inherited cardiac arrhythmia syndrome group may have been slightly underpowered. An accurate a priori power analysis was difficult to calculate due to the lack of relevant child literature that allowed calculation of effect sizes. A post hoc power analysis indicated that the study was somewhat underpowered. However, it is one of the largest studies to date in this population group (across adults, children and parents), and the sample size is very respectable given the rarity of the syndromes. The $80 \%$ recruitment rate suggests it is representative of children attending specialist inherited cardiac arrhythmia clinics.

The current study included children who had different inherited cardiac arrhythmia syndromes and children who had a family history of different inherited cardiac arrhythmia syndromes. Levels of anxiety may differ according to what inherited cardiac arrhythmia syndrome a child has or has a family history of.

The recruitment rate is much lower $(31 \%)$ for the control group, and due to the lack of demographic data, it is not possible to see how those that responded responders' compare to the school as a whole. The lower recruitment rate is likely to be because participating as a control required more effort. Children had to take the forms home from school, parents had to sign consent forms and then the children had to bring them back to school before the children could participate. In the specialist inherited cardiac arrhythmia clinic, parents could sign the consent forms in clinic and the children could immediately participate. It is possible these children who gained consent within the school sample are not representative of normal children. These children may have had particular motivations to get the consent forms returned. For example, the children may have come from more anxious families, and therefore, the family were more interested in research on anxiety, or the children may have come from families where physical health problems are present leading to an interest in research on anxiety within a physical health context. An opt-out procedure may have increased the recruitment rate and thus the representativeness of the control sample. However, this was not considered an ethical procedure by the ethics board.

\section{CONCLUSION}

The CAQ has promising psychometric properties in a child population. However, the retest reliability and norms/cut-offs in a child population need to be established before the CAQ can be used routinely in clinical practice. Children with a cardiac arrhythmia syndrome and children who have a family history who have experienced an SCD in the immediate family are at risk of experiencing anxiety. These children should be targeted for routine screening and offered psychological input where necessary.

Contributors ANL conducted this research for her thesis during her clinical psychology doctorate. JE and RS were the field supervisors for the thesis. T0 and HP were the academic supervisors for the thesis. JPK is the consultant cardiologist in the clinic where the research took place.

Funding This study was supported by the National Institute for Health Research Biomedical Research Centre at Great Ormond Street Hospital for Children NHS Foundation Trust and University College London.

Disclaimer The views expressed are those of the author and not necessarily those of the NHS, the NIHR or the Department of Health.

\section{Competing interests None declared.}

Patient consent Parental/guardian consent obtained.

Ethics approval This study was given favourable opinion by the Camden and Kings Cross National Health Service Research Ethics Committee. It was also granted Management Approval by the Great Ormond Street Research and Development Office. This study was also given favourable opinion by the Royal Holloway, University of London, Research Ethics Committee.

Provenance and peer review Not commissioned; externally peer reviewed.

Data sharing statement The raw data are stored by Great Ormond Street Hospital. There are no additional unpublished data.

Open access This is an open access article distributed in accordance with the Creative Commons Attribution Non Commercial (CC BY-NC 4.0) license, which permits others to distribute, remix, adapt, build upon this work non-commercially, and license their derivative works on different terms, provided the original work is properly cited, appropriate credit is given, any changes made indicated, and the use is non-commercial. See: http://creativecommons.org/licenses/by-nc/4.0/.

\section{REFERENCES}

1. Giudici V, Spanaki A, Hendry J, et al. Sudden arrhythmic death syndrome: diagnostic yield of comprehensive clinical evaluation of pediatric first-degree relatives. Pacing Clin Electrophysiol 2014;37:1681-5.

2. Stewart JL, Mishel MH. Uncertainty in childhood illness: a synthesis of the parent and child literature. Sch Inq Nurs Pract 2000;14:299-319.

3. Meulenkamp TM, Tibben A, Mollema ED, et al. Predictive genetic testing for cardiovascular diseases: impact on carrier children. $A m \mathrm{~J}$ Med Genet A 2008;146A:3136-46.

4. Giuffre RM, Gupta S, Crawford SG, et al. Fears and anxiety in children with long-QT syndrome compared to children with asthma. J Natl Med Assoc 2008;100:420-4. 
5. Eifert G, Zvolensky M, Lejuez C. Heart focussed anxiety and chest pain: a conceptual and clinical review. Clinical Psychology: Science and Practice 2000;7:403-17.

6. Barlow DH. Anxiety and its disorders. New York: Guildford Press, 1988.

7. Clark DM. A cognitive approach to panic. Behav Res Ther 1986;24:461-70.

8. Eifert GH, Thompson RN, Zvolensky MJ, et al. The cardiac anxiety questionnaire: development and preliminary validity. Behav Res Ther 2000;38:1039-53.

9. Silverman WK, Fleisig W, Rabian B, et al. Childhood anxiety sensitivity index. J Clin Child Psychol 1991;20:162-8.
10. Chorpita BF, Yim L, Moffitt C, et al. Assessment of symptoms of DSM-IV anxiety and depression in children: a revised child anxiety and depression scale. Behav Res Ther 2000;38:835-55.

11. Chorpita BF, Moffitt CE, Gray J. Psychometric properties of the Revised Child Anxiety and Depression Scale in a clinical sample. Behav Res Ther 2005;43:309-22.

12. Tabachnick B, Fidell L. Using Multivariate Statistics. 5th edn. New York: Harper Collins, 2007.

13. Bennett S, Shafran R, Coughtrey A, et al. Psychological interventions for mental health disorders in children with chronic physical illness: a systematic review. Arch Dis Child 2015;100:308-16.

14. Eifert GH, Lau AW. Using behavioral experiments in the treatment of cardiophobia: a case study. Cogn Behav Pract 2001;8:305-17. 